\title{
Artificial muscles powered by glucose
}

\author{
Fariba Mashayekhi Mazar ${ }^{1,2}$, Jose G. Martinez ${ }^{1}$, Manav Tyagi ${ }^{1}$, Mahdi Alijanianzadeh ${ }^{3}$, Anthony P.F. \\ Turner $^{1 \#}$, Edwin W. H. Jager ${ }^{1 *}$ \\ ${ }^{1}$ Department of Physics, Chemistry and Biology (IFM), Linköping University, Linköping, Sweden. \\ ${ }^{2}$ Malek-Ashtar University of Technology, Tehran, Iran. \\ ${ }^{3}$ Department of Cell \& Molecular Biology, Faculty of Biological Sciences, Kharazmi University, Tehran, Iran
}

\author{
*E-mail: edwin.jager@liu.se \\ \# Current address: Professor Emeritus, SATM, Cranfield University, Bedfordshire, MK430AL, UK.
}

\begin{abstract}
Untethered actuation is important for many robotic devices to achieve autonomous motion, which is typically enabled by using batteries. However, this results in extra weight for the device and the need to regularly recharge the battery. Using enzymes to provide the required electrical charge is particularly interesting as it will enable faster recharging and direct harvesting of fuel components from a surrounding fluid. The latter is an advantage towards applications in implantable and ingestible devices and environmental monitoring of aqueous environments containing metabolizable carbon. Here, we present a soft artificial muscle that uses biofuels (glucose and oxygen) to drive the actuator. Enzymes integrated in the actuator catalytically convert glucose and oxygen into electrical power that in turn is converted into movement by the electroactive polymer polypyrrole causing the actuator to bend. Aspergillus
\end{abstract} niger glucose oxidase enzyme combined with tetrathiafulvalene $7,7,8,8$ tetracyanoquinodimethane (TTF/TCNQ) and laccase enzyme from Trametes versicolor with 2,2'-azinobis-(3-ethylbenzothiazoline-6-sulfonic acid) (ABTS) formed the integrated bioelectrode pair. The performance of the glucose $/ \mathrm{O}_{2}$ bioelectrode pair showed a maximum 
open circuit voltage of $0.70 \pm 0.04 \mathrm{~V}$ at room temperature and a maximum power density of $0.27 \mu \mathrm{W} \mathrm{cm} \mathrm{cm}^{-2}$ at $0.50 \mathrm{~V}$, enough to drive an external polypyrrole-based trilayer artificial muscle. Next the enzymes were fully integrated into the artificial muscle, resulting in an autonomously powered actuator that could bend reversibly in both directions driven by glucose and $\mathrm{O}_{2}$ only. This autonomously powered artificial muscle could be of great interest for soft (micro-)robotics and implantable or ingestible medical devices that need to manoeuvre throughout the body, for devices in regenerative medicine (tissue culture), for wearables, and to allow environmental monitoring devices to operate autonomously in aqueous (and possibly certain gaseous) environments.

Keywords: Glucose oxidase; Laccase; TTF-TCNQ; ABTS; Artificial muscle, PVDF; Polypyrrole; Electroactive polymers

\section{Introduction}

Autonomous movement is an essential capability in living organisms. It allows the individual species to grasp and manipulate objects, as well as to move, to escape danger, find food, or meet other individuals. Nature has developed various means that enable movement and locomotion, from protein motors that drive cilia to specialised muscle tissue, all autonomous and self-powered. In mammalian muscles, glucose and oxygen $\left(\mathrm{O}_{2}\right)$ are consumed to generate adenosine triphosphate (ATP) by aerobic respiration. The ATP, being converted to adenosine diphosphate (ADP) due to hydrolysis, in turn drives the nanoscopic conformational changes in the myosin heads with respect to the actin filaments that cause the macroscopic muscle contraction and elongation. ${ }^{1}$ In contrast, human-made contraptions such as industrial or humanoid robots are typically driven by classical actuators that use electrical, pneumatic, or thermal means and are often tethered or require large batteries. Driving actuators, or artificial 
muscles, directly using biofuels such as glucose, is highly anticipated. It would enable (soft) robotic devices to be fuelled by green, biofuels such as glucose, methane or alcohol and open up possibilities for driving implants or injectable vehicles in the body without the need for batteries or external charging sources such as by radiofrequency (RF) coils.

Analogous to the mammalian muscles, we demonstrate here artificial, polymer muscles driven by glucose and $\mathrm{O}_{2}$. Soft, artificial muscles have been reported based on dielectric elastomers, ${ }^{2}$ conducting polymers, ${ }^{3,4}$ carbon nanotubes ${ }^{5,6}$ and even fishing lines ${ }^{7}$ and textiles, ${ }^{8}$ but they still all are driven by electrical or thermal means. Conducting polymer artificial muscles are interesting as they are operated at low voltages and behave similarly to mammalian muscle. During oxidation and reduction, conducting polymers change their volume - as well as other material properties such as colour (electrochromism) ${ }^{9}$, wettability ${ }^{10}$ and adhered protein conformation $^{11}$ - which is used to construct actuators. The volume change is based on the dimensional changes that occur as a result of electrochemically induced ion insertion and desertion, along with associated solvating species, ${ }^{12,13}$ accompanied by conformational changes in polymeric chains. ${ }^{14}$ Artificial muscles based on conducting polymers come in many configurations, one of which is the so-called trilayer or bimorph configuration (Fig. 1A), which we use here to demonstrate the principle. The conducting polymer, e.g. polypyrrole (PPy) or poly(3,4-ethylenedioxythiophene) (PEDOT), is sandwiched on two sides of a flexible membrane. ${ }^{15,16}$ A potential difference is applied between the two conducting polymer layers, electrochemically oxidizing the conducting polymer on one side and reducing the conducting polymer on the other side. This causes one layer to shrink and the other to swell, thus resulting in a bending motion. However, these artificial muscles are still driven by an external, often tethered electrical power source. Direct conversion of chemical energy into electrical energy to drive these biomimetic machines would be the most elegant solution and would capitalise on the efficiencies already achieved by nature. Catalysts such as enzymes can achieve such 
direct conversion and are, for instance, integrated in bioelectrodes. Coupled as a pair such bioelectrodes can form a biofuel cell which can generate electrical power from biofuels. ${ }^{17}$ The power output of biofuel cells can drive microdevices that need relatively low power. ${ }^{18}$ Bioelectrodes that convert Glucose and $\mathrm{O}_{2}$ respectively are particularly interesting as they enable autonomous power generation in physiological fluids because glucose is present in all organs, thus eliminating the need to pump fuel. Also $\mathrm{O}_{2}$ is present in all organs, thus removing the need for air supply through a membrane at the cathode compartment. ${ }^{19}$ Several research groups have used glucose as a biofuel. For example, Mano and Heller reported biological motion in presence of glucose and oxygen to move a carbon fibre using glucose oxidase (GOx) and bilirubin oxidase to create a $\mathrm{H}^{+}$flux that drove the fibre. ${ }^{20}$ Movement of carbon nanotubes was achieved by using GOx and catalase to generate hydrogen peroxide which in turn was catalysed into $\mathrm{O}_{2}$ bubbles that propelled the nanotubes. ${ }^{21}$ Miyake et al. report a biofuel cell that used fructose and $\mathrm{O}_{2}$ as fuels. ${ }^{22}$ It was prepared by modifying fructose dehydrogenase and bilirubin oxidase on carbon nanotube-decorated carbon fibre fabrics and could drive lightemitting diodes. A pacemaker powered by a glucose $/ \mathrm{O}_{2}$ biofuel cell was presented by MacVittie et al. ${ }^{23}$ Strack et al used enzymes in solution to construct a biochemical logic circuit to control a chemical actuator. ${ }^{24}$ However, despite these advances, artificial muscles are still being driven using external means.

Here, we present a polymer artificial muscle powered by glucose and $\mathrm{O}_{2}$ biofuels in which enzymatic electrodes are fused with the polymer artificial muscle to create an integrated bionic system. The artificial muscle was based on a PPy trilayer actuator using dodecylbenzenesulphonate (DBS) as the dopant. A tetrathiafulvalene $7,7,8,8$ tetracyanoquinodimethane (TTF/TCNQ)/Aspergillus niger glucose oxidase enzyme modified $\mathrm{Au}$ electrode and 2,2'-azinobis-(3-ethylbenzothiazoline-6-sulfonic acid) (ABTS)/laccase enzyme from Trametes versicolor modified Au electrode were used as the bioelectrodes. 


\section{Methods}

\subsection{Chemicals}

Glucose oxidase EC 1.1.3.4, from Aspergillus niger, laccase enzyme of Trametes versicolor, 2,2'-azinobis-(3-ethylbenzothiazoline-6-sulfonic acid) (ABTS), and tetrathiafulvalene 7,7,8,8tetracyanoquinodimethane (TTF/TCNQ) were purchased from Sigma-Aldrich. Pyrrole (from SAFC®, acquired through Sigma-Aldrich) was distilled under vacuum prior to use and stored at $-20{ }^{\circ} \mathrm{C}$. Porous poly (vinylidene fluoride) (PVDF) with $0.45 \mu \mathrm{m}$ pore size and a thickness of $110 \mu \mathrm{m}$ (Immobilon-P) was acquired from Sigma-Aldrich, and Sodium dodecylbenzene sulfonate (NaDBS) was obtained from TCI, Japan. Graphite was purchased from Merck (Germany). D-(+)-glucose, $\mathrm{NH}_{3}(98 \%)$, and $\mathrm{H}_{2} \mathrm{O}_{2}$ (30\%) were purchased from VWR. Potassium phosphate dibasic anhydrous $\left(\mathrm{K}_{2} \mathrm{HPO}_{4}\right)$, Potassium dihydrogen phosphate $\left(\mathrm{KH}_{2} \mathrm{PO}_{4}\right)$, Sodium acetate and glacial acetic acid were obtained from Merck (Germany). All solutions were prepared using $18 \mathrm{M} \Omega \mathrm{DI}$ water (Milli-Q).

\subsection{Bioelectrode fabrication and characterisation}

The bioelectrodes acting as working electrodes and containing enzymes and mediators were prepared by immobilizing the constituent materials onto a $0.5 \mathrm{~cm} \times 0.5 \mathrm{~cm} \mathrm{Au} / \mathrm{Si}$ electrode. First, the bare $\mathrm{Au}$ electrode surfaces were cleaned by immersion in $\mathrm{NH}_{3}, \mathrm{H}_{2} \mathrm{O}_{2}$, and DI water $(1: 1: 5)$ at $85^{\circ} \mathrm{C}$ for 10 minutes and thereafter washed gently with DI water. For the bioanode

\footnotetext{
${ }^{a}$ NOTE: The definition of the cathode and anode depends on whether the system is regarded as a galvanic cell or electrochemical cell. Since we are combining two cell types into a fused device this definition can become confusing. We have used the following conventions: The bioanode is the electrode where glucose is oxidized and electrons are transferred into the electrode, and the biocathode is the electrode where $\mathrm{O}_{2}$ is reduced and electrons are transferred from the electrode (following classical biofuel cell definition). The cathode is the electrode that reduces PPy (by donating electrons) and the anode is the electrode that oxidizes PPy (by accepting electrons).
} 
preparation, $10 \mu \mathrm{L}$ of TTF/TCNQ was drop cast on the Au electrode and dried at room temperature for $15 \mathrm{~min}$. Then $10 \mu \mathrm{L}$ GOx enzyme solution $\left(5 \mathrm{mg} \mathrm{ml}^{-1}\right)$ was deposited onto the TTF-TCNQ/Au surface and gently dried under airflow in a laminar flow hood for $15 \mathrm{~min}$. The biocathode $^{\mathrm{a}}$ was prepared by pipetting $10 \mu \mathrm{L}$ of a $0.002 \mathrm{M}$ ABTS solution and drying at room temperature for $15 \mathrm{~min}$. After that, $10 \mu \mathrm{L}$ of laccase solution $\left(5 \mathrm{mg} \mathrm{ml}^{-1}\right)$ was cast on the ABTS/Au support and gently dried under airflow in a laminar flow hood for 15 min. For the bioelectrodes integrated on the artificial muscle, $10 \mu \mathrm{L}$ of reduced graphene oxide (RGO) was drop cast as a barrier on both sides of each bioelectrode before adding mediators and enzymes. The RGO was synthesized from graphite through a modified Hummers' method ${ }^{25}$.

Electrochemical measurements were performed at room temperature using an Ivium compactstat or IviumStat Potentiostat/Galvanostat (Eindhoven, The Netherlands) in a threeelectrode electrochemical cell, which included a modified $\mathrm{Au} / \mathrm{Si}$ electrode as the working electrode, a piece of $\mathrm{Au} / \mathrm{Si} 3 \mathrm{~cm} \times 3 \mathrm{~cm}$ as the counter electrode and a BASi MF-2052 $\mathrm{Ag} / \mathrm{AgCl}$ (3 $\mathrm{M} \mathrm{KCl})$ reference electrode. Cyclic voltammograms were performed in a cell containing 5 $\mathrm{ml}$ of $0.1 \mathrm{M}$ phosphate buffer solution (PBS), pH 5.0 at $100 \mathrm{mV} \mathrm{s}^{-1}$, over potential ranges from $-0.50 \mathrm{~V}$ to $0.50 \mathrm{~V}$ for the bioanode and $0 \mathrm{~V}$ to $1 \mathrm{~V}$ for the biocathode. The electrochemical properties of the anodic and cathodic electrodes were obtained in the absence and presence of $0.1 \mathrm{M}$ glucose (dissolved in $0.1 \mathrm{M} \mathrm{PBS}$ ) and air saturation (after $30 \mathrm{~min}$ bubbling air) respectively.

To assess possible power generation both bioelectrodes were submerged in a beaker filled with $20 \mathrm{ml}$ of $0.1 \mathrm{M}$ PBS (pH 5.0) with 0.1 M glucose and saturated with air (30 min). The electrodes consisted of $1 \mathrm{~cm} \times 1 \mathrm{~cm}$ pieces of an Au coated silicon wafer. The TTF-TCNQ/GOx served as the bioanode for the oxidation of glucose and mediated electron transfer. The ABTS/laccase

Thus, the bioanode is the cathode and the biocathode the anode with respect to the electrochemical actuator and as used in Figures 3-5. 
served as the biocathode for reduction of $\mathrm{O}_{2}$ by mediated electron transfer. The bioanode and biocathode were combined thus de facto forming a classical membrane-less biofuel cell, and Figure 1B illustrates its mechanism. The complete cell was allowed to equilibrate at open circuit potential (OCP) before measurements were performed. ${ }^{26}$

The OCP of the bioelectrode pair was investigated over a period of 7 days. The electrodes were stored at room temperature and the OCP checked regularly using a potentiostat/galvanostat (Ivium compactstat) with a very high input impedance (>1000 G $\Omega$ ). For the stability test, an external load of $1 \mathrm{M} \Omega$ was connected between the two electrodes. The power output of the cell in the stability tests was calculated from the potential and resistance values according to Ohm's law.

\subsection{Artificial muscle preparation}

For the preparation of the artificial muscle, a thin Au film was sputtered on both sides of a piece of PVDF membrane using a Vacutec Plasma Systems Sputter at a pressure of 4.6 mTorr, $36.6 \mathrm{~cm}^{3} / \mathrm{min}$ Ar flow and a sputter rate of $5 \mathrm{~nm} / \mathrm{min}$ for $5 \mathrm{~min}$. Next, PPy was synthesized electrochemically on both sides of $\mathrm{Au} / \mathrm{PVDF} / \mathrm{Au}$ membrane at a $+0.6 \mathrm{~V}$ vs $\mathrm{Ag} / \mathrm{AgCl}$, by immersing the membrane in a solution containing $0.1 \mathrm{M}$ pyrrole and $0.1 \mathrm{M}$ NaDBS. For the electrosynthesis, each side of Au/PVDF/Au was connected to the working electrode separately, a stainless-steel mesh $(2 \mathrm{~cm} \times 7 \mathrm{~cm})$ was used as the counter electrode, and the same $\mathrm{Ag} / \mathrm{AgCl}$ reference electrode as a previous was used. A typical chronoamperogram of the PPy synthesis on one side of Au/PVDF/Au for 3000 seconds is shown in Supplementary Information (SI), Figure S1A. After PPy electropolymerisation on both sides, strips of $0.5 \mathrm{~cm} \times 2 \mathrm{~cm}$ were cut, resulting in $\mathrm{PPy} / \mathrm{Au} / \mathrm{PVDF} / \mathrm{Au} / \mathrm{PPy}$ trilayer artificial muscles ${ }^{27}$. The artificial muscles were actuated in $0.1 \mathrm{M}$ NaDBS solution and 0.1 M PBS ( $\mathrm{pH}$ 5.0) at room temperatures using cyclic voltammetry (CV) and chronoamperometry (Figs. S1B-E). CVs of the PPy/Au/PVDF/Au/PPy 
artificial muscle were taken over the potential range-1.7 V to $0.50 \mathrm{~V}$ (in $0.1 \mathrm{M} \mathrm{NaDBS}$ ) and $1.2 \mathrm{~V}$ to $0.2 \mathrm{~V}$ (in $0.1 \mathrm{M}$ PBS, $\mathrm{pH} 5.0$ ), in both cases with a scan rate of $20 \mathrm{mV} \mathrm{s}^{-1}$. The chronoamperometric activation of the PPy/Au/PVDF/Au/PPy artificial muscle was performed at a constant potential of $-0.45 \mathrm{~V}$ (in $0.1 \mathrm{M} \mathrm{NaDBS}$ ) and $-0.50 \mathrm{~V}$ (in $0.1 \mathrm{M}$ PBS, pH 5.0).

\subsection{Enzyme-driven artificial muscles}

The artificial muscle was fabricated integrating the enzymes in 4 different configurations to investigate different properties, and with increasing complexity and increasing integration. i) The enzymes as bioelectrodes externally connected to the artificial muscle; ii) the enzymes integrated on artificial muscle as a single, separated bioelectrode directly connected to each side of the PPy/Au/PVDF/Au/PPy actuator (i.e. bioanode on one side and biocathode on the other side), iii) with fully integrated enzymes on each side of the actuator, and finally iv) with the enzymes as a bioelectrode pair on each side, but mirrored (i.e. anode-cathode pair on one side and cathode-anode pair on the other side). The fabrication of the artificial muscle with the integrated enzyme-bioelectrodes combines the fabrication steps as described in section 2.2 and 2.3. Sketches of the configurations are included in each figure.

\subsection{Artificial muscle driven by external potentiostat}

To investigate the function of artificial muscle before connecting to the external bioelectrodes, the motion of PPy/Au/PVDF/Au/PPy trilayer artificial muscle was surveyed using the potentiostat in chronoamperometric mode for 2 cycles of $0 \mathrm{~V}$, for $300 \mathrm{~s}$ and $-0.70 \mathrm{~V}$ for $300 \mathrm{~s}$ in two different electrolytes 0.1 M NaDBS and 0.1 M PBS (pH 5.0), respectively. The potential range of $0 \mathrm{~V}$ to $-0.70 \mathrm{~V}$ was chosen to simulate the maximum $\mathrm{OCP}$ potential. After showing good performance of the artificial muscle movement using the potentiostat, the 
$\mathrm{PPy} / \mathrm{Au} / \mathrm{PVDF} / \mathrm{Au} / \mathrm{PPy}$ trilayer artificial muscle was connected to the external bioelectrodes and characterized. This movement experiment was run for around 4 hours.

All the movements were recorded using a Digital Microscope (Dino-Lite AM785MZT). All images in Figures 3-5 are merged from two frame grabs as indicated by the dashed line. The original figures are found in the SI.

\section{Results and Discussion}

\subsection{External enzyme-bioelectrodes}

First, the individual, external enzyme-bioelectrodes were investigated. Each step of the surfacemodified $\mathrm{Au} / \mathrm{Si}$ electrode was verified by the $\mathrm{CV}$ experiments in $0.1 \mathrm{M}$ PBS (pH 5.0), in the absence and presence of glucose with scan rate of $100 \mathrm{mV} \mathrm{s}^{-1}$. Figure S2A-curve a shows the CV obtained with the bare-Au electrode as a control experiment. The TTF-TCNQ-modified Au electrode produced a current of $13.14 \mu \mathrm{A} \mathrm{cm}^{-2}$ at a potential of $0.16 \mathrm{~V}$ and this peak was ascribed to the redox processes of TTF-TCNQ adsorbed on the Au electrode (Fig. S2A-curve b) ${ }^{28}$ As shown in Figure S2A-curve c, after casting GOx enzyme on the electrode forming TTF-TCNQ/ GOx, the current reached to $88.8 \mu \mathrm{A} \mathrm{cm}^{-2}$ at potential of $0.32 \mathrm{~V}$ and along with the increase in anodic current, there was a decrease in the cathodic peak at $0 \mathrm{~V}$. After adding the glucose, the electrocatalytic current reached to $262 \mu \mathrm{A} \mathrm{cm}{ }^{-2}$ for $0.1 \mathrm{M}$ glucose at potential of $0.32 \mathrm{~V}$, showing that the bioanode exhibited a good bioelectrocatalytic activity for the oxidation of glucose (Fig. S2A- curve d).

Figure S2B shows the CV of the biocathode under the same conditions as for the bioanode experiment, i.e. in 0.1 M PBS (pH 5.0), and in the absence and presence of $\mathrm{O}_{2}$ at a scan rate of $100 \mathrm{mV} \mathrm{s}^{-1}$. The bare-Au electrode was investigated as a control (Fig. S2B-curve a). When the bare-Au electrode was modified with ABTS, the current of the ABTS/Au electrode increased to $16.84 \mu \mathrm{A} \mathrm{cm}^{-2}$ at a potential of $0.64 \mathrm{~V}$ (Fig. S2B-curve b). Thereafter laccase was chemically 
bound to the ABTS/Au electrode, and the current increased to $27.15 \mu \mathrm{A} \mathrm{cm} \mathrm{cm}^{-2}$ at a potential of $0.62 \mathrm{~V}$ (Fig. S2B-curve c). Finally, operation in the air-saturated 0.1 M PBS (pH 5.0) showed an increase of the peak current to $33.31 \mu \mathrm{A} \mathrm{cm}^{-2}$ at potential of $0.58 \mathrm{~V}$, which was close to the redox potential of laccase and ABTS $^{29}$ (Fig. S2B-curve d), with well-defined cathodic waves attributed to the reduction of $\mathrm{O}_{2}$ by the laccase. The results indicate that laccase electrochemically catalysed the reduction of $\mathrm{O}_{2}$ through the mediated electron transfer reaction between the active centre of laccase and the electrode.

Next, the bioelectrode pair was inserted (without a separating membrane) in a $0.1 \mathrm{M}$ glucose and 30 min air-saturated $0.1 \mathrm{M}$ PBS $(\mathrm{pH} \mathrm{5.0)}$ at room temperature. Figure 2A shows the polarization curves of TTF-TCNQ/GOx-modified $\mathrm{Au}$ electrode (curve a) and the laccase/ABTS-modified Au electrode (curve b). As expected, the recorded OCP of $0.70 \pm 0.04$ V corresponds to the difference between the individually measured OCPs of the bioanode (Fig. 2A-curve a) and the biocathode (Fig. 2A-curve b). Figure 2B presents the OCP of the cell when the cell was operated continuously for 7 days. The cell OCP decreased by $20 \%$ per day and reached $0.15 \mathrm{~V}$ at day 7 . This drop could be due to the consumption of glucose and $\mathrm{O}_{2}$. The variation of the power density as a function of the cell voltage presents the typical bell-shaped curve observed by others ${ }^{30,31}$, with a maximum of $0.27 \mu \mathrm{W} \mathrm{cm}{ }^{-2}$ at $0.50 \mathrm{~V}$ in $0.1 \mathrm{M}$ PBS (pH 5.0) (Fig. 2C). The cell voltage under an external load of $1 \mathrm{M} \Omega$ resistance, was recorded for 27 hours, operating in the $0.1 \mathrm{M}$ PBS ( $\mathrm{pH}$ 5.0). When the cell was operated continuously under this load, it lost $25 \%$ of its original power in the first $12 \mathrm{~h}$ and the power output dropped by $50 \%$ after a 27 hours continuous work. The cell voltage decreased slowly to $0.10 \mathrm{~V}$ (Fig. 2D). It was observed that the bioelectrode pair retained $60 \%$ of its initial power density up to 3 days when it was operated continuously. The decline in power density output after 3 days might be caused by a loss of mediators and enzymes, since they were not covalently attached to the electrodes. 


\subsection{Artificial muscle driven by external bioelectrodes}

Before connecting the artificial muscle to the external enzyme-bioelectrodes, the muscle's performance was checked using an external potentiostat in two different electrolytes, $0.1 \mathrm{M}$ NaDBS and 0.1 M PBS (pH 5.0) using both CV and chronoamperometry (Figures S1B-E). As can be seen in Figure S3 the actuator showed the normal reversible movement as previously seen for such trilayer actuators, indicating that the actuator was functioning correctly. The movement was reduced in the physiological PBS electrolyte as compared to simple NaDBS salt solution, which is consistent with previous results using cerebral physiological solutions ${ }^{32}$. Operating at a slightly lower $\mathrm{pH}$ should not influence its performance. ${ }^{33}$

Having established that the bioelectrode pair can deliver sufficient potential difference $(\sim 0.70$ V) and power to drive a trilayer actuator ${ }^{34}$ and that the actuator operated normally, we connected the PPy/Au/ PVDF/Au/PPy trilayer artificial muscle to the external bioelectrodes. As can be seen in Figure 3, the movement of artificial muscle driven by the external bioelectrodes is clear. At $\mathrm{T}_{0}$, the initial position, the artificial muscle was connected to the bioelectrodes and the muscle bent towards the anodic ${ }^{\mathrm{a}}$ side as would be expected. ${ }^{35}$ On the anodic side PPy(DBS) was oxidised and shrank and on the cathodic ${ }^{\mathrm{a}}$ side $\mathrm{PPy}(\mathrm{DBS})$ is reduced and swelled, thus causing a bending to the left. The position of the artificial muscle after 4 hours is indicated by point $\mathrm{T}_{1}$ showing a $5 \mathrm{~mm}$ displacement.

\subsection{Artificial muscles with integrated catalytic bioelectrodes}

Next, we integrated the bioelectrodes on the PPy/Au/PVDF/Au/PPy trilayer artificial muscle. The separate bioanode was integrated at the top on one side of the actuator and likewise the separate biocathode was integrated at the top on the opposing side. In the integrated device we initially found some leakage and mixing of the bio-anode and -cathode materials through the 
porous PVDF membrane and to ensure better retention, an additional RGO layer was introduced as a barrier between the bio-anode and -cathode. This resulted in the required performance. When inserted into the glucose $/ \mathrm{O}_{2}$ containing electrolyte the actuator started to move directly. Figure $4 \mathrm{~A}$ shows the movement upon insertion into the glucose $/ \mathrm{O}_{2}$ containing electrolyte. As with the external bioelectrodes, the muscle bent $2 \mathrm{~mm}$ towards the anode side demonstrating that the bio-catalytic electrodes can be integrated with the artificial muscle. Thereafter we fully integrated the enzymes onto the entire artificial muscle. The movement of the now self-powered PPy/Au/PVDF/Au/PPy artificial muscle is shown in Figure 4B. Again, the displacement occurred towards the anode side, moving clearly from its starting position $\mathrm{T}_{0}$ to the final position $T_{1}$ after 3 hours with a total displacement of $3 \mathrm{~mm}$. Figure $4 \mathrm{C}$ shows the displacement over time of the fully integrated artificial muscle. It shows the typical displacement profile as seen for CP actuators which are diffusion limited, although slower than when driven by an external power supply.

To check whether the actuator is truly driven by faradaic reactions at the catalytic bioelectrodes three control experiments were performed. First, the actuator without any bioelectrodes was inserted into the biofuel-containing electrolyte (Fig. S4A). Next, the actuator with the fully integrated bioelectrodes was inserted in DI water (Fig. S4B) and in a $\mathrm{N}_{2}$ saturated 0.1 M PBS (pH 5.0) (Fig. S4C), respectively, that is two solutions without any biofuel. In neither of the three cases any movement could be observed, indicating that indeed the movement was caused by the catalytic conversion of $\mathrm{O}_{2}$ and glucose.

A single movement towards one side only has only limited applications, for instance as a singleuse valve. To be useful as self-powered artificial muscle to drive (soft robotic) devices, reversible movement of the actuator is required. To achieve this, we integrated an anode and cathode on both the top and bottom of each side of PPy/Au/PVDF/Au/PPy trilayer artificial muscle, but in a mirrored configuration. We inserted the integrated muscle into the solution 
while keeping the top electrode pair above the water level (i.e. inactive). As previously, the muscle bent towards the anode side that is to the left, displacing $2.5 \mathrm{~mm}$ in 3 hours (from $\mathrm{T}_{0}$ to $\mathrm{T}_{1}$ in Figure 5A). Next, we rotated the muscle so that the inserted electrode pair went above the water level and non-inserted electrode pair came under the water level thus de facto changing the polarity of the inserted bioelectrodes and thus reversing the electrochemical reactions in the PPy layers. The left side, which was now the cathode side, was reduced and the PPy(DBS) layer swelled and the right side, now the anode, was oxidised and shrunk. This resulted into a bending motion to the right, returning to the original position (from $T_{2}$ to $T_{3}$ in 3 hours) as shown in Figure 5B, i.e. a reversible self-powered artificial muscle.

\section{Conclusions}

We have demonstrated that enzyme-based bioelectrodes that use glucose and $\mathrm{O}_{2}$ could power artificial muscles. The immobilization of the enzymes with redox mediators resulted a potential difference over the bioelectrodes of more than $0.50 \mathrm{~V}$, which was sufficient to drive an externally connected actuator. In a glucose and air saturated $0.1 \mathrm{M}$ PBS (pH 5.0), a maximum power density of $0.27 \mu \mathrm{W} \mathrm{cm}{ }^{-2}$ was measured at room temperature. The OCP of catalytic bioelectrode pair was $0.70 \mathrm{~V} \pm 0.04 \mathrm{~V}$. The stability of the bioelectrodes was tested for around 27 hours with a load of $1 \mathrm{M} \Omega$. We then demonstrated an autonomously powered artificial muscle by integrating the catalytic bioelectrodes. These self-powered artificial muscles showed reversible motion in both directions. The bioelectrodes manufactured according to this process have good stability and are promising candidates to autonomously drive artificial muscles. In this work we demonstrated for the first time the principle of self-powered artificial muscles using the body's principal biofuel.. To enhance the biofuel powered actuator performance, including speed, power output stability (e.g. by improved immobilisation, engineering the enzymes) and the magnitude of the generated potential (as increasing the potential difference 
will increase the speed of actuation ${ }^{34}$ ) need to be increased, for instance by better integration of the enzymes and optimisation of the ratio of biocathode/anode materials and conducting polymer. We used the trilayer actuator configuration, which range of motion can be improved by optimising the actuator design (e.g. using a softer, more flexible membrane, optimising the ratio between the three actuator layers ${ }^{36}$ ) to exemplify biofuel-powered artificial muscles as a bending motion is clearly visible, but this is only one possible configuration of conducting polymer artificial muscles. The concept can be generalised to other artificial muscle configurations. Linear actuation ${ }^{8}$ and complex devices comprising multiple actuators ${ }^{4}$ are especially interesting future targets. The Laccase and Glucose Oxidase reactions might have asymmetric electron transfer, which could result in non-symmetric movements, which is not visible in trilayer actuators since the bimorph design with two identical PPy layers ensures symmetric deflection. To get a symmetric charge transfer one would for instance need to optimise the ratio between Laccase and Glucose Oxidase enzymes and/or adjust the mediators that assist in the charge transfer from the enzyme to the conducting polymer layer Here we used the body's principal biofuel glucose, but the same concept can be extended to using other in vivo fuels or even other biofuels present in the environment to enable autonomous propulsion of robots that can "swim" through lakes taking samples for environmental monitoring. We envision a future where biofuel-powered artificial muscles offer an efficient solution for much needed silent autonomous propulsion in soft microrobots, ingestible devices and implantable artificial muscles.

\section{Acknowledgements}

This work was financially supported by Linköping University, Carl Tryggers Stiftelse (CTS16:207), Swedish Research Council (2014-3079), and the EU Marie Curie Actions Initial Training Network 'MICACT' (641822). FMM acknowledges the Ministry of Science Research 
and Technology of Iran (www.msrt.ir) to support her research exchange at Linkoping University. We thank Filip Wiltgren for his assistance with the figures.

\section{References}

1 Grabowski, S. R. \& Tortora, G. J. Principles of anatomy and physiology. (Wiley, 2000).

2 Pelrine, R., Kornbluh, R., Pei, Q. \& Joseph, J. High-speed electrically actuated elastomers with strain greater than 100\%. Science 287, 836-839 (2000).

3 Smela, E., Inganäs, O. \& Lundström, I. Controlled folding of micrometer-size structures. Science 268, 1735-1738 (1995).

4 Jager, E. W., Inganäs, O. \& Lundström, I. Microrobots for micrometer-size objects in aqueous media: potential tools for single-cell manipulation. Science 288, 2335-2338 (2000).

5 Baughman, R. H. et al. Carbon nanotube actuators. Science 284, 1340-1344 (1999).

6 Foroughi, J. et al. Torsional carbon nanotube artificial muscles. Science 334, 494-497 (2011).

7 Haines, C. S. et al. Artificial muscles from fishing line and sewing thread. science 343, 868-872 (2014).

8 Maziz, A. et al. Knitting and weaving artificial muscles. Science advances 3, e1600327 (2017).

9 Vidal, F. et al. Poly(3,4-ethylenedioxythiophene)-containing semi-interpenetrating polymer networks: A versatile concept for the design of optical or mechanical electroactive devices. Polymer International 59, 313-320 (2010).

10 Isaksson, J., Tengstedt, C., Fahlman, M., Robinson, N. \& Berggren, M. Solid-state organic electronic wettability switch. Adv. Mater. 16, 316-320 (2004).

11 Svennersten, K., Bolin, M., Jager, E. W. H., Berggren, M. \& Richter-Dahlfors, A. Electrochemical modulation of epithelia formation using conducting polymers. Biomaterials 30, 6257-6264, doi:10.1016/j.biomaterials.2009.07.059 (2009).

12 Pei, Q. \& Inganäs, O. Electrochemical applications of the bending beam method. 1. Mass transport and volume changes in polypyrrole during redox. The Journal of Physical Chemistry 96, 10507-10514 (1992).

13 Bay, L., Jacobsen, T., Skaarup, S. \& West, K. Mechanism of actuation in conducting polymers: osmotic expansion. The Journal of Physical Chemistry B 105, 8492-8497 (2001).

14 Otero, T. F. \& Martinez, J. G. Artificial muscles: a tool to quantify exchanged solvent during biomimetic reactions. Chemistry of Materials 24, 4093-4099 (2012).

15 Vidal, F., Plesse, C., Teyssié, D. \& Chevrot, C. Long-life air working conducting semiIPN/ionic liquid based actuator. Synthetic Metals 142, 287-291 (2004).

16 Zhou, D. et al. Solid state actuators based on polypyrrole and polymer-in-ionic liquid electrolytes. Electrochimica acta 48, 2355-2359 (2003).

17 Falk, M. Direct electron transfer based biofuel cells. Operation in vitro and in vivo 1 (2014).

18 Pizzariello, A., Stred'ansky, M. \& Miertuš, S. A glucose/hydrogen peroxide biofuel cell that uses oxidase and peroxidase as catalysts by composite bulk-modified bioelectrodes based on a solid binding matrix. Bioelectrochemistry 56, 99-105 (2002). 
19 Heller, A. Miniature biofuel cells. Physical Chemistry Chemical Physics 6, 209-216 (2004).

20 Mano, N. \& Heller, A. Bioelectrochemical propulsion. Journal of the American Chemical Society 127, 11574-11575 (2005).

21 Pantarotto, D., Browne, W. R. \& Feringa, B. L. Autonomous propulsion of carbon nanotubes powered by a multienzyme ensemble. Chemical Communications, 15331535 (2008).

22 Miyake, T., Haneda, K., Yoshino, S. \& Nishizawa, M. Flexible, layered biofuel cells. Biosensors and Bioelectronics 40, 45-49 (2013).

23 MacVittie, K. et al. From "cyborg" lobsters to a pacemaker powered by implantable biofuel cells. Energy \& Environmental Science 6, 81-86 (2013).

24 Strack, G. et al. Artificial Muscle Reversibly Controlled by Enzyme Reactions. The Journal of Physical Chemistry Letters 1, 839-843, doi:10.1021/jz100070u (2010).

25 Marcano, D. C. et al. Improved synthesis of graphene oxide. ACS nano 4, 4806-4814 (2010).

26 Arechederra, R. \& Minteer, S. Complete oxidation of glycerol in an enzymatic biofuel cell. Fuel Cells 9, 63-69 (2009).

27 Jager, E. W. et al. Patterning and electrical interfacing of individually controllable conducting polymer microactuators. Sensors and Actuators B: Chemical 183, 283-289 (2013).

28 Harris, A. R., Zhang, J., Cattrall, R. W. \& Bond, A. M. Applications of voltammetric ion selective electrodes to complex matrices. Analytical Methods 5, 3840-3852 (2013).

29 Bourbonnais, R., Leech, D. \& Paice, M. G. Electrochemical analysis of the interactions of laccase mediators with lignin model compounds. Biochimica et Biophysica Acta (BBA)-General Subjects 1379, 381-390 (1998).

30 Chen, Y., Gai, P., Zhang, J. \& Zhu, J.-J. Design of an enzymatic biofuel cell with large power output. Journal of Materials Chemistry A 3, 11511-11516 (2015).

31 Zebda, A. et al. Mediatorless high-power glucose biofuel cells based on compressed carbon nanotube-enzyme electrodes. Nature communications 2, 370 (2011).

32 Daneshvar, E. D. \& Smela, E. Characterization of Conjugated Polymer Actuation under Cerebral Physiological Conditions. Advanced Healthcare Materials 3, 1026-1035, doi:10.1002/adhm.201300610 (2014).

33 Shimoda, S. \& Smela, E. The effect of $\mathrm{pH}$ on polymerization and volume change in PPy (DBS). Electrochimica acta 44, 219-238 (1998).

34 Lewis, T. W., Spinks, G. M., Wallace, G. G., Mazzoldi, A. \& De Rossi, D. Investigation of the applied potential limits for polypyrrole when employed as the active components of a two-electrode device. Synthetic Metals 122, 379-385 (2001).

35 Pei, Q. \& Inganäs, O. Electrochemical applications of the bending beam method. 2. Electroshrinking and slow relaxation in polypyrrole. The Journal of Physical Chemistry 97, 6034-6041 (1993).

36 Benslimane, M., Gravesen, P., West, K., Bay, L. \& Skaarup, S. in 7th International Conference on New Actuators. 635-638. 

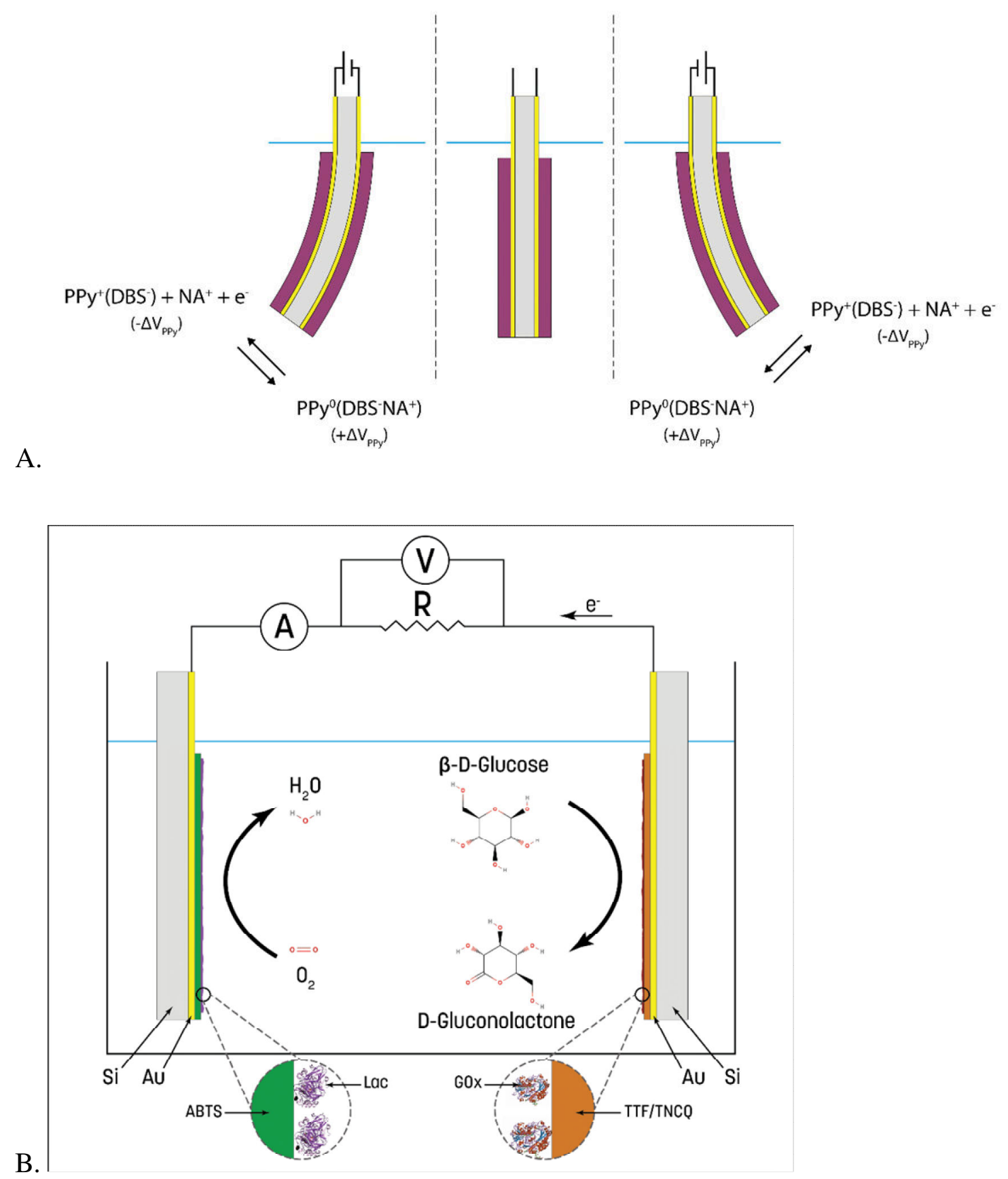

Figure 1. Working principles of a trilayer artificial muscle and bioelectrodes. (A)

Schematic description of the functioning of a 'trilayer' conducting polymer actuator or artificial muscle. (B) Schematic description of the bioelectrode pair producing electricity to power e.g. artificial muscles. 

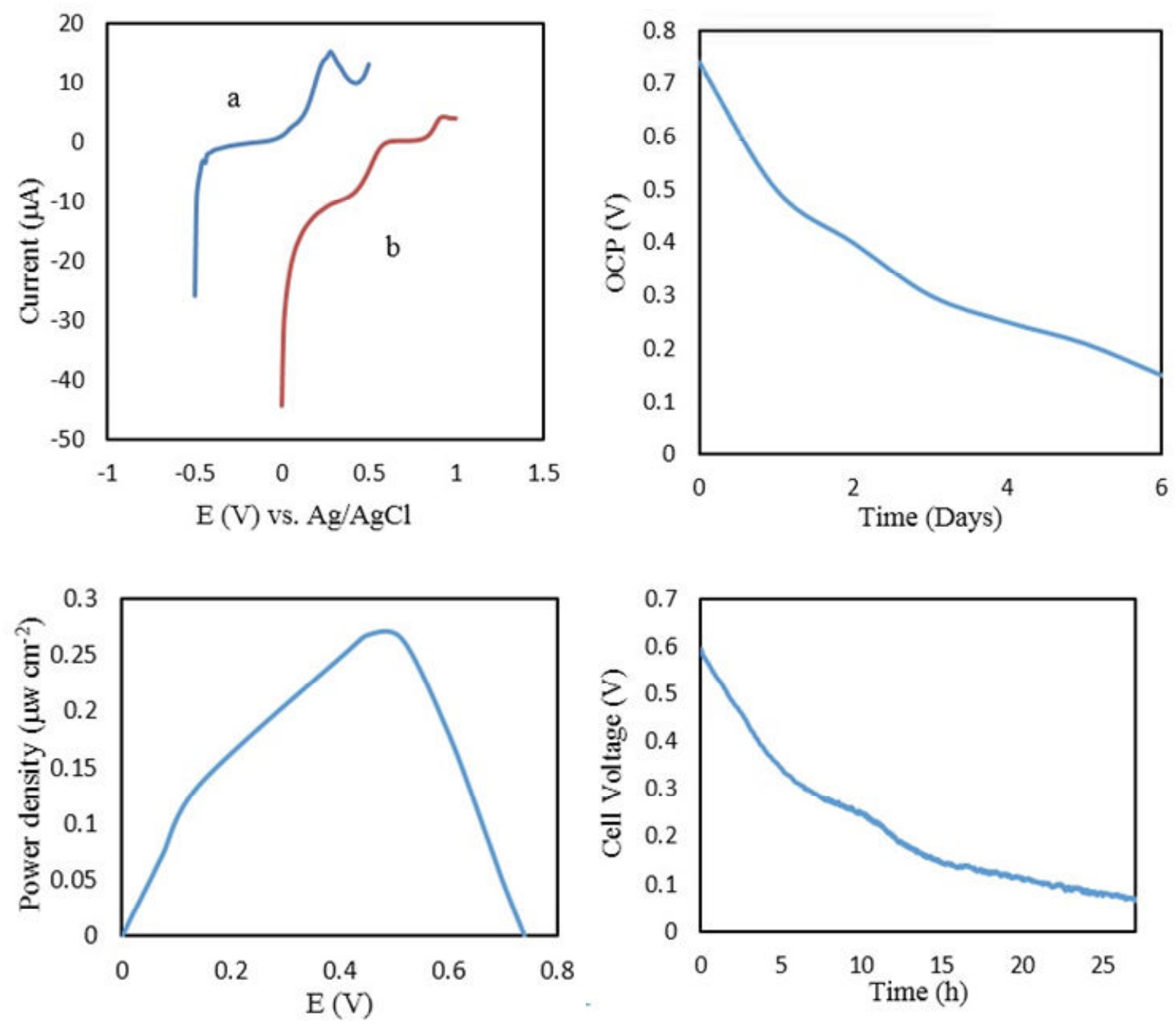

Figure 2. Bioelectrode characterization. (A) Polarization curves of modified electrodes. (a) The GOx/TTF-TCNQ-modified Au electrode (curve a) and (b) the laccase/ABTS-modified Au electrode (curve b). (B) Dependence the OCP of the bioelectrode pair on time. (C) The dependence of power density on the voltage of the bioanode TTF-TCNQ/GOx and biocathode ABTS/laccase pair in 0.1 M PBS (pH 5.0) with an air-saturated solution and 0.1 $\mathrm{M}$ of glucose. (D) The stability of the enzyme-bioelectrodes over time with an external load of $1 \mathrm{M} \Omega$ resistance. 


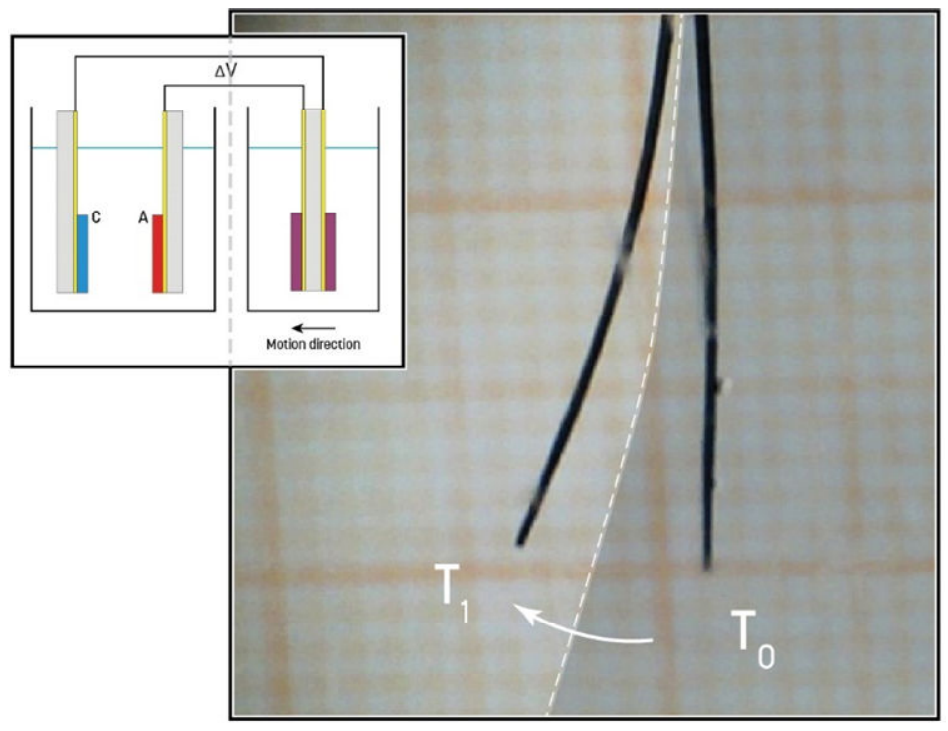

Figure 3. Proof of principle an artificial muscle driven by an external bioelectrode pair. Movement of the PPy/Au/PVDF/Au/PPy trilayer artificial muscle driven by the external bioelectrodes. $T_{0}$ is the initial position when connecting the bioelectrode pair to the actuator and $\mathrm{T}_{1}$ is the final position after $4 \mathrm{~h}$ showing that the bioelectrodes have powered the artificial muscle causing it to bend towards the anode side with a $5 \mathrm{~mm}$ displacement. (The image is merged from two frame grabs as indicated by the dashed line.) 

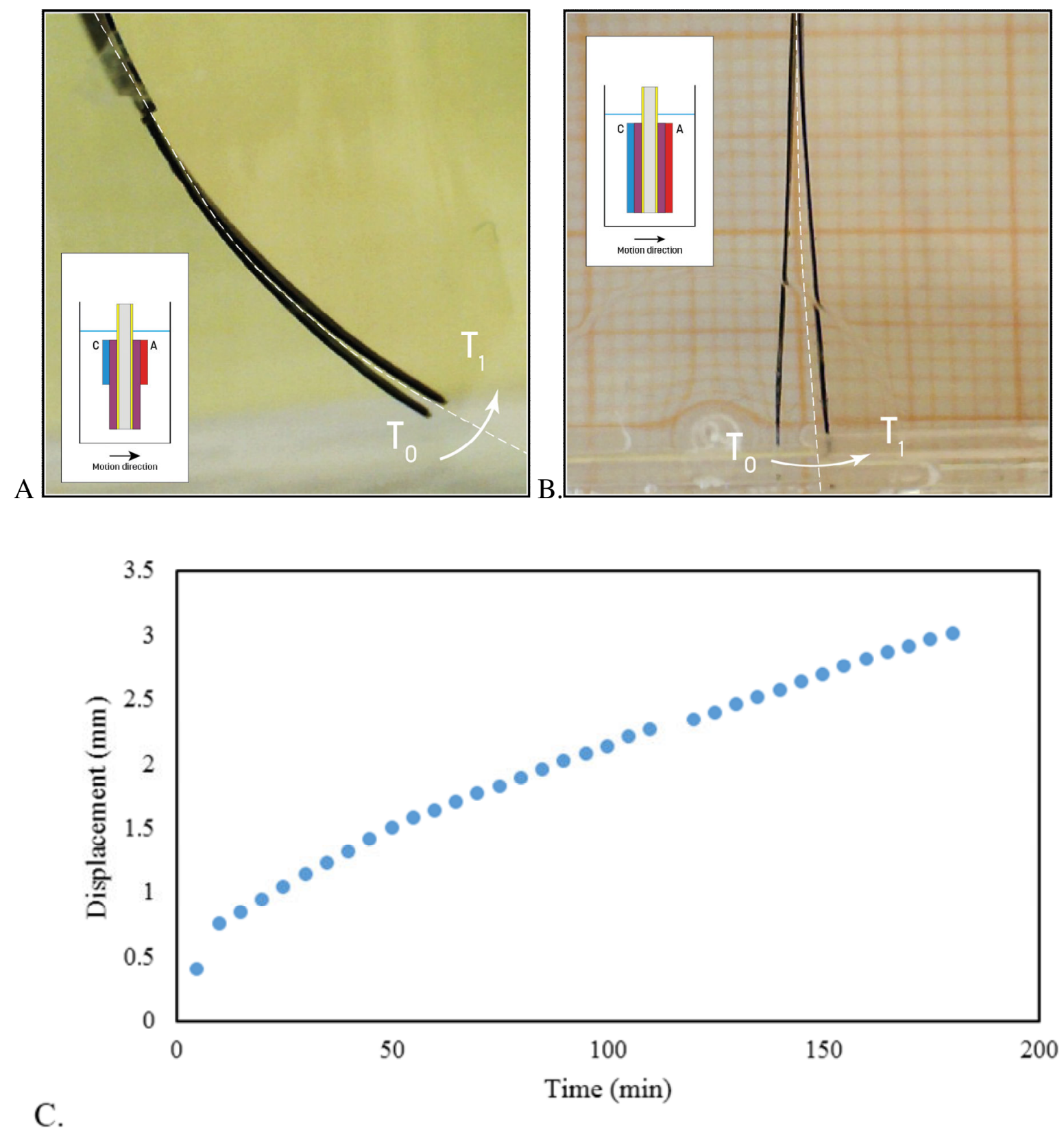

Figure 4. Bioelectrode integrated artificial muscles. (A) The movement of the $\mathrm{PPy} / \mathrm{Au} / \mathrm{PVDF} / \mathrm{Au} / \mathrm{PPy}$ with two separated bioelectrodes integrated on the top. $\mathrm{T}_{0}$ initial position of artificial muscle and $\mathrm{T}_{1}$ position after 3 hours, showing a $2 \mathrm{~mm}$ displacement. (B) The movement of the artificial muscle with the fully integrated bioelectrodes. $\mathrm{T}_{0}$ is starting position and $\mathrm{T}_{1}$ the position after 3 hours. The actuator moved $3 \mathrm{~mm}$ to the anode side. (see videos in SI) (C) The displacement versus time of the actuator with fully integrated bioelectrodes of (B). 

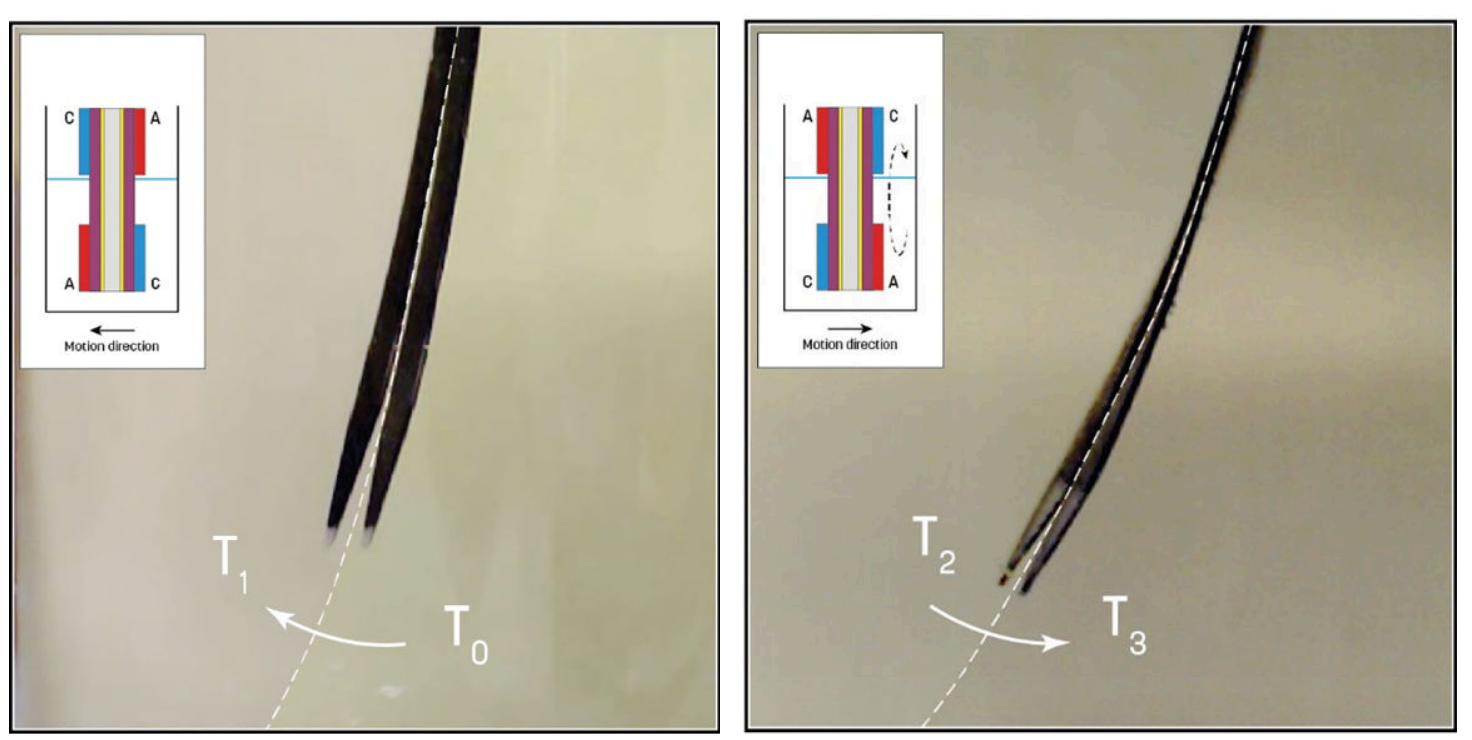

Figure 5. Artificial muscle with double bioelectrode pair to simulate on/off switching. (A) The artificial muscle is inserted into the electrolyte with only one bioelectrode pair submerged. The actuator bent towards the left, the anode side for $2.5 \mathrm{~mm}$, from $\mathrm{T}_{0}$ to $\mathrm{T}_{1}$, after 3 hours. (B) Next, the actuator was rotated, and the other electrode pair was submerged. The artificial muscle now bent back to the right, towards the anode, which was the former cathode position, from $\mathrm{T}_{2}$ to $\mathrm{T}_{3}$, again after 3 hours. 


\title{
Cranfield University
}

2019-06-19

\section{Artificial muscles powered by glucose}

\author{
Mashayekhi Mazar, Fariba
}

Wiley

Mazar FM, Martinez JG, Tyagi M, et al., (2019) Artificial muscles powered by glucose.

Advanced Materials, Volume 31, Issue 32, 2019, Article number 1901677

https://doi.org/10.1002/adma.201901677

Downloaded from Cranfield Library Services E-Repository 